\title{
Dietary and nutritional approach to do the Rioja Bike Race: case study
}

\author{
Enfoque dietético-nutricional para afrontar la Rioja Bike Race: caso práctico \\ José Miguel Martínez Sanz ${ }^{1-2}$, José Antonio López Gómez ${ }^{3}$, Aurora Norte Navarro ${ }^{1-2}$, \\ Alejandro Martinez-Rodriguez ${ }^{4}$ \\ 1 Research Group on Food and Nutrition (ALINUT). University of Alicante, Spain. \\ 2 Nursing Department. Faculty of Health Sciences. University of Alicante, Spain. \\ 3 Sport Clinic. Barcelona, Spain. \\ 4 Department of Analytical Chemistry, Nutrition and Food Science. Faculty of Sciences. University of Alicante, Spain.
}

CORRESPONDENCIA:

Recepción: junio 2017 • Aceptación: enero 2018

Alejandro Martínez Rodríguez

amartinezrodriguez@ua.es

\begin{abstract}
The Rioja Bike Race is an individual mountain bike competition that is carried out in 3 stages, with variable distances $(60-83 \mathrm{~km})$. The event provides refreshment areas and technical assistance to meet the nutrition and hydration needs of the participants. The dietarynutritional preparation is of great importance in order to reduce or even prevent gastrointestinal problems, dehydration, hyponatremia, fatigue, among others. The aim of this case study is to describe the dietary and nutritional planning of an athlete in this event. Test subject: Male, 37 years old and 10 years of sports experience and very important sport achievements. His eating habits, supplement intake and body composition were evaluated. For nutrition planning of the Rioja Bike Race, we took into account the dietary and nutritional recommendations for athletes in competition, test time, refreshment areas and possible food intake / supplements. The dietary-nutritional planning in ultra-endurance events is important for successful performance in the competition, to decrease nutritional risk and avoiding dehydration, fatigue, gastrointestinal disturbances, etc.
\end{abstract}

Key words: sport, ultra-endurance, nutrition, dietary supplements, Rioja bike race.

\section{Resumen}

Rioja Bike Race es una competición individual de BTT que se realiza en 3 etapas de distancias variables (60-83km). El evento cuenta con áreas para atender las necesidades de nutrición e hidratación de los participantes. La importancia de la preparación dietético-nutricional radica en la prevención o disminución de problemas gastrointestinales, deshidratación, hiponatremia, fatiga, entre otros. El objetivo es describir la planificación dietéticonutricional de un deportista que afronta este evento. Varón de 37 años con 10 años de experiencia deportiva, en el que se evaluaron los hábitos alimentarios, ingesta de suplementos, composición corporal. Para la planificación nutricional de la Rioja Bike Race, se tuvieron en cuenta las recomendaciones dietético-nutricionales para la competición, tiempo medio, lugar de los avituallamientos e ingesta de alimentos/suplementos. La planificación dietéticonutricional en eventos de ultraresistencia es un condicionante para realizar satisfactoriamente la prueba para disminuir riesgos nutricionales como la deshidratación, fatiga, molestias gastrointestinales, etc.

Palabras clave: deporte, ultraresistencia, nutrición, suplementos dietéticos, Rioja bike race. 


\section{Introduction}

The Rioja bike race is an individual mountain bike competition with different stages formed of three marathons. The competition is held in Logroño, La Rioja (Spain) with a duration of at least 6 hours (Zaryski \& Smith, 2005), where the athletes require previous physical, mental and dietetic preparation for the event (Jeukendrup, 2011). It is important to note that there is a time limit of one hour to pass by each point control, intersection control, refreshment station, exit and arrival; after each time period the service will close. All of these have all the supplies required in order to cover for all the participants food and hydration needs during the stages. The first stage has a distance of $60.81 \mathrm{~km}$ with refreshment points at the $24^{\text {th }}$ and $39^{\text {th }}$ kilometer. The distance of the second stage consists of $82.69 \mathrm{~km}$ and the refreshment points are located at the $22^{\text {nd }}, 38^{\text {th }}$ and $68^{\text {th }}$ kilometer mark. The third and final stage spread throughout 66.47 kilometers with refreshment points at the $18^{\text {th }}$ and $48^{\text {th }} \mathrm{km}$ mark (Rioja Bike Race, 2015).

In these types of endurance competitions, the body experiments an increase in the muscles' capacity to oxidize fat and economize the use of glycogen in order to improve their performance during the activity (Jeukendrup, 2011). The relative use of fats and carbohydrates during exercise can have considerable variations depending on the intensity of the exercise and the adaptation of each individual athlete (GonzálezHaro, Galilea, González-de-Suso, Drobnic, \& Escanero, 2007). Both the volume and the level of intensity during sports practice will allow us to know the demands and requirements of the athlete when training and on the day of the competition (Barrero, Chaverri, Erola, Iglesias, \& Rodríguez, 2014).

The current nutritional recommendations for sporting events, establish an intake in the 2-3 days prior to the competition of 8-12 grams of carbohydrates per $\mathrm{Kg}$ of body weight a day, and $1-4 \mathrm{~g} / \mathrm{Kg}$ of body weight of carbohydrates 1 to 4 hours prior to the event. During physical activity whilst the event is taking place the established average hourly intake is $500 \mathrm{ml}$ of liquid and 30-90g of carbohydrates. Post activity as nutritional recovery it is recommended to ingest liquids (1.25 to $1.5 \mathrm{~L}$ of fluids for every $1 \mathrm{~kg}$ body weight loss), carbohydrates (1-1,5g/kg of body weight), proteins ( 0.25 to $0.3 \mathrm{~g} / \mathrm{kg}$ body weight or $15-25 \mathrm{~g}$ ) (Martínez Sanz \& Urdampilleta Otegui, 2013; Australian sports comission, 2019; Urdampilleta, Martínez-Sanz, Sanchez, \& Herms, 2013). The nutritional dietary preparation is highly important to be able to avoid problems ingestion related problems during these types of tests. The effort needed to go through mountain passes during the activities are associated with onset fatigue and a decrease in race rhythm due to the depletion of muscle glycogen, especially after the first two hours (Jeukendrup, 2011). This creates the need to ingest carbohydrates before and during the test, as fuel input (Martinez-Sanz, Urdampilleta, \& MielgoAyuso, 2013). The natural loss of body liquid through sweating together with an inadequate ingestion of liquids can trigger dehydration (Urdampilleta et al., 2013). Hyponatremia is another factor to be considered, possibly produced by an excessive intake of water which replaces part of the liquids lost while in activity, but not the electrolytes, leading to a diluted concentration of electrolytes in the blood (Urdampilleta et al., 2013). Finally, it is important to mention gastrointestinal problems like nausea, vomiting, gases or diarrhea may be present caused by an excess or deficiency of liquids, food or ergo-nutritional aids or by ingestion of any of these without trying it before (Australian Sports Comission, 2019). However, all of these can be avoided using a correct nutritional dietary planning.

The aim of this clinical case is to describe the nutritional dietary planning of a male cyclist in facing the Rioja Bike Race of May 2015.

\section{Clinical Case}

Profile of the patient

- Male, 37 years old, +10 years sports experience in high endurance events who has acquired very popular sporting achievements (1st Spaniard finish Ultraman Canada and Ultraman Hawaii). He attended a dietary consultation in April 2015 for nutritional planning for the Rioja Bike Race (15 th $17^{\text {th }}$ of May, 2015) in La Rioja (Spain). The athlete was informed and asked for his consent in agreement with the Helsinki 2013 declaration, which he agreed upon.

\section{Evaluation and Intervention}

An evaluation of his eating habits, training characteristics and food/liquid/supplement consumption was made. His body composition was evaluated following the methodology of the International Society for the Advancement of Kinanthropometry (ISAK) (Cabañas Armesilla \& Esparza Ros, 2009), with the following results: $86,10 \mathrm{~kg}, 1,89 \mathrm{~m}$, $\Sigma 8$ skin folds :63mm, 9,87\% of fat mass $(8,49 \mathrm{~kg}), 77,61 \mathrm{~kg}$ of lean mass and central somatotype. 
For the nutritional dietary planning, the macronutrients intake recommendations during the previous days of the sporting event were followed as prescribed (Australian Sports Comission, 2019), as well as, the carbohydrates $(\mathrm{CH})$, liquids and sodium intake per hour during competition $(6,7)$. A diet was established 24 hours before the competition of $5460 \mathrm{kcal}, 794 \mathrm{~g}$ of $\mathrm{CH}(9.23 \mathrm{~g} / \mathrm{kg}), 215 \mathrm{~g}$ of protein $(2.5 \mathrm{~g} / \mathrm{kg})$ and $158 \mathrm{~g}$ of fat. On the day of the competition, breakfast was eaten 3 hours before, composed of 1000kcal, 154g of $\mathrm{CH}(1.79 \mathrm{~g} / \mathrm{kg}), 25 \mathrm{~g}$ of proteins and $32 \mathrm{~g}$ of fat as well as an intake $30-60 \mathrm{~min}$ previous of $500 \mathrm{ml}, 40 \mathrm{~g}$ of $\mathrm{CH}$ and $150 \mathrm{mg}$ caffeine ( 1 vial, $25 \mathrm{ml}$ ).

An average time of 4-5 hours per stage was estimated, according to the average rhythm performed by the athlete in other similar competitions, the sport material, refreshments and intake of food/liquids/supplements that could be taken were considered. The following quantities were the ones that were established in the dietary plan. For each hour of exercise an approximate intake of $500-800 \mathrm{ml}$ of liquid and $500-1000 \mathrm{mg}$ of sodium needed to be consumed. Additionally, during the first hour of exercise, an average intake of $30 \mathrm{~g}$ of $\mathrm{HC}$ needed to be ingested and $60 \mathrm{~g}$ of $\mathrm{HC}$ in the second hour. From the third hour on the replenishment of the athlete's nutrients would be done through the intake of water, Replenishing Drink (BR), gels, sports bars and food. In addition, a post-effort nutritional recovery was contemplated, based on the intake of $\mathrm{HC}$ and proteins (Martínez Sanz \& Urdampilleta Otegui, 2013; Australian Sports Comission, 2019; Urdampilleta et al., 2013). The calibration of macronutrients was made using the Dietsource 3.0 software with the nutritional information of the consumed supplements.

Table 1 shows the intake done by the athlete during each hour of the event, the nutritional value of the intake of this intake (food and supplements) and annotations of the locations of each of the refreshment stations provided by the event's organization. On the next day of the test completion, we evaluated in a verbal manner (through a phone call) if the nutritional requirements had actually been fulfilled by the athlete. He confirmed to meeting $100 \%$ of the guidelines established (food, liquid and supplements intake). The athlete took with him what needed to be consumed, and used the water available in the refreshment stations to prepare the BR, by mixing one single-dose stick of BR with water inside a sports bottle.

During the evaluation, the athlete indicated that he had demonstrated good tolerance and that he had not felt any gastrointestinal inconveniences, cramps, or decrease in his performance; in contrast to other competitions where he had not received any nutritional advice.

\section{Discussion}

After the analysis of the clinical case, it's important to pay attention to the results obtained after a specific nutritional dietary planning focused towards a high endurance event like the current one. In this aspect, it can be observed how the athlete follows without difficulties the established guidelines by the dieticiannutritionist, since the sensations he manifested were of good tolerance of the intake of food/liquids/supplements, absence of cramps and lack of gastrointestinal discomfort. Moreover, he indicated that his efforts and performance during the event were not as affected or diminished as in other trials.

On the one hand, no evidence other than the literature provided was observed (Knechtle, 2014) that could negatively influence the athletic performance of the athlete. The athlete presented values of body composition according to the recommendations for the sports practice of the test (Zaryski \& Smith, 2005). In addition, training conditions and loads were applied following the recommendations for this type of event, the environmental conditions did not influence the athlete or his performance. Therefore, the distance and the level of difficulty, in theory, more likely to condition athletic performance, were also handled favorably.

On the other hand, the energetic-nutritional recommendations for athletes were applied (Martínez-Sanz et al., 2013), accompanied by an adequate sport planning, both days before and during the competition (Barrero et al., 2014), that condition the sports performance directly. Regarding the dietary-nutritional preparation, emphasize the absence of gastrointestinal discomfort and dehydration due to an adequate intake of food/supplements and electrolyte replenishment (Rehrer, 2001; Urdampilleta et al., 2013).

The food and supplements chosen to carry out the dietary planning were those that the athlete usually took in this type of tests and had good tolerance for. The taking of food and/or supplements that could be acquired from the refreshment stations (except for water) was not prescribed. The reason behind this was that the information (inside the website) about which foods/liquids/supplements would make up the supplies provided was found inadequate (Rioja Bike Race, 2015). Given the lack of knowledge about the composition of the refreshments that were going to be provided, in wanting to prevent gastrointestinal discomfort to the athlete, it was decided not to take into account the supplies from the stations into the dietary planning, so as not to consume products that had not been previously tested (Prado de Oliveira E \& Jeukendrup A, 
Table 1. Information of sports nutrition products and dietary-nutritional planning of Rioja Bike Race.

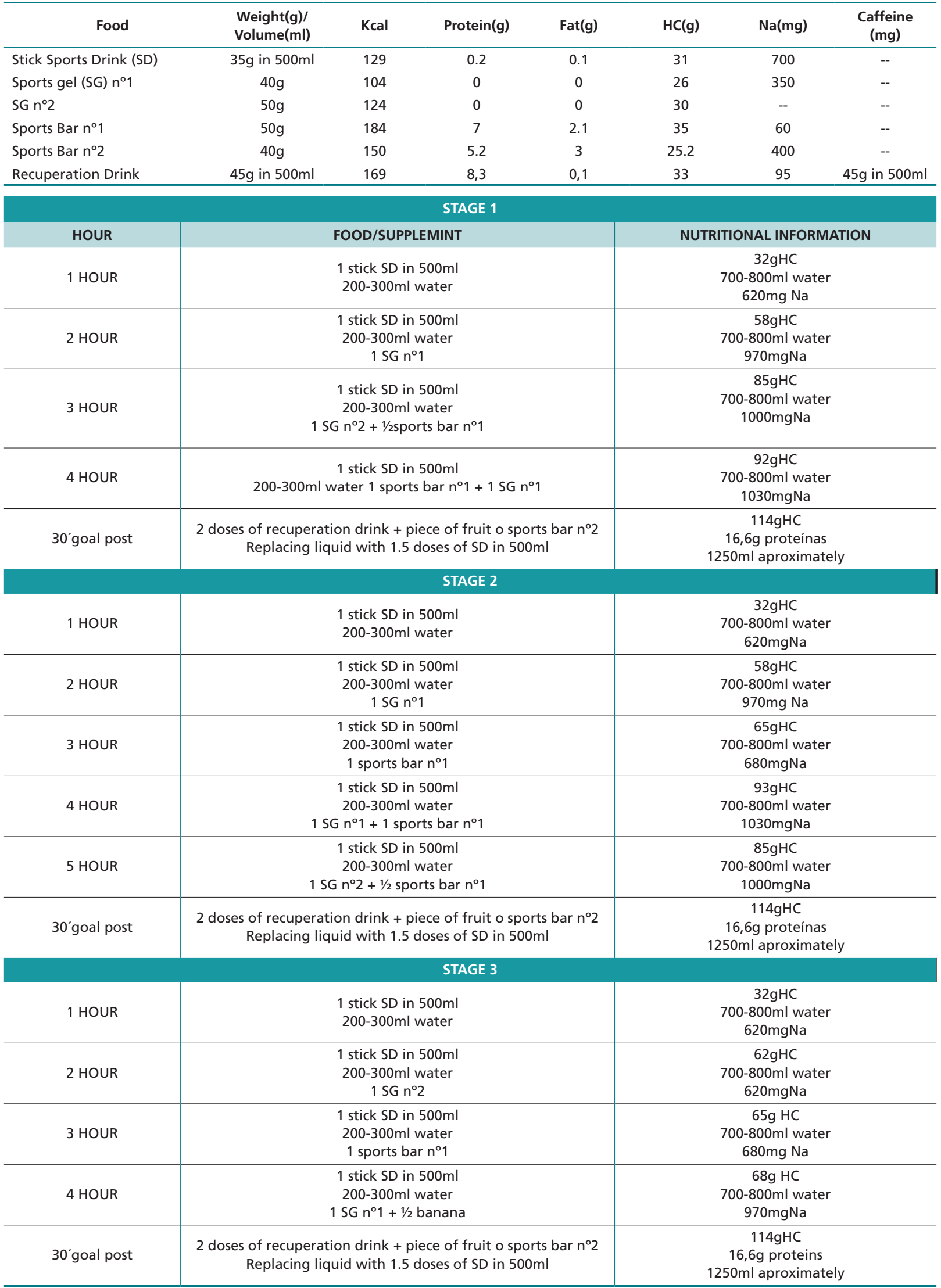

Na:sodium; Stick: single-dose sachets to mix with wáter; ml:total fluid intake with SD and wáter. 
2013). This meant that the athlete had to carry with him what he was going to ingest throughout the race. The only supply he could take from the refreshment stations was water when he finished the one he was carrying and had to prepare the BR with the single serve pod stick, in order to continue replenishing the liquid consumed (Urdampilleta et al., 2013). In spite of this obstacle, the overall sensation of the athlete was one of good tolerance in the intake, absence of discomfort, satisfactory rhythm and performance in the race.

It is noteworthy to mention some differences between the established dietary prescription and the dietetic-nutritional recommendations in ultra-endurance sports events. It is recommended to ingest up to $90 \mathrm{~g}$ of $\mathrm{HC}$ for each hour of exercise through foods or supplements that provide glucose and fructose as a source of $\mathrm{HC}$, alternating between solids and liquids, and making a fluid replacement of between $0.4-0.8 \mathrm{~L} / \mathrm{h}$ (Thomas, Erdman, \& Burke, 2016; Urdampilleta, A et al., 2013). In our case study, a gradual intake of carbonHC was ingested. During the first hour; ingesting $32 \mathrm{~g}$ of $\mathrm{HC} ; 60-80 \mathrm{~g} / \mathrm{HC} / \mathrm{h}$ between the second and third hour and reaching up to $90 \mathrm{~g} / \mathrm{HC} /$ hour from the fourth hour. A water intake of approximately 0.7$0.8 \mathrm{~L} /$ hour was also maintained by drinking the 'replenishing drink' and water, however, the weight variation could not be measured as an indirect marker of hydration status (Australian Sports Comission, 2019; Urdampilleta, et al., 2013). The intake of the 'replenishing drink' and water helped the replacement of salts, mainly sodium, but the level of sodium in plasma was not measured to verify that there was no risk of hyponatremia (Urdampilleta et al., 2013). It was planned in this way so that the athlete could adapt progressively to the intake, because he had commented that eating a larger volume or amount of food/liquid/supplements from the beginning of the event, could cause some discomfort. Although differences exist, the plan was adapted as much as possible to the recommendations according to the preferences and possibilities of intake of the athlete (Rehrer, 2001; Urdampilleta et al., 2013; Zaryski \& Smith, 2005).

\section{Conclusion}

Thus, the dietary-nutritional strategies to handle with success a test of these characteristics, seems to be beneficial. For proper planning, the characteristics of the athlete, sports event, equipment, refreshments available and possibilities of food/liquid/supplements intake must be taken into account. Furthermore counseling by a dietitian-nutritionist is essential to reduce the incidence of adverse effects and gastrointestinal discomfort. It would be interesting to extrapolate this type of interventions together with physical, physiological and psychological parameters to other ultraresistant test that prove limiting on many occasions.

The description of this type of case studies is important as an educational tool for other dietician-nutritionists who advise athletes that compete in this type of events.

\section{REFERENCES}

Barrero, A., Chaverri, D., Erola, P., Iglesias, X., \& Rodríguez, F. A. (2014) Intensity profile during an ultra-endurance triathlon in relation to testing and performance. International Journal of Sports Medicine, 35(14), 1170-1178. https://doi.org/10.1055/s-0034-1374601

Cabañas Armesilla, M. D., \& Esparza Ros, F. (2009). Compendio de cineantropometria. Madrid, España: CTO MEDICINA.

La Rioja Bike Race. Retrieved Dec 12, 2015, from http://www.lariojabikerace.com/es/

Australian Sports Commission. Australia. Sports Supplement. Retrieved May 12, 2019, from https://www.sportaus.gov.au/_data/assets/pdf_ file/0004/698557/AIS_Sports_Supplement_Framework_2019.pdf

González-Haro, C., Galilea, P. A., González-de-Suso, J. M., Drobnic, F., \& Escanero, J. F. (2007). Maximal lipidic power in high competitive level triathletes and cyclists. British Journal of Sports Medicine, 41(1), 23-28. https://doi.org/10.1136/bjsm.2006.029603

Jeukendrup, A. E. (2011). Nutrition for endurance sports: Marathon, triathlon, and road cycling. Journal of Sports Sciences, 29 Suppl 1, S9199. https://doi.org/10.1080/02640414.2011.610348

Knechtle, B. (2014). Relationship of anthropometric and training characteristics with race performance in endurance and ultra-endurance athletes. Asian Journal of Sports Medicine, 5(2), 73-90.

Martínez-Sanz, J. M., Urdampilleta, O. A., \& Mielgo-Ayuso, J. (2013) Necesidades energéticas, hídricas y nutricionales en el deporte. European Journal of Human Movement, (30), 37-52.
Martínez-Sanz, J. M., \& Urdampilleta, O. A. (2013). Nutrición. Planifica tu alimentación a través del material deportivo. Sport Training Magazine, (50), 44-47.

Prado de Oliveira, E., \& Jeukendrup, A. (2013). Nutritional recommendations to avoid gastrointestinal complaints during exercise. Sports Science Exchange, 114, 1-4.

Rehrer, N. J. (2001). Fluid and electrolyte balance in ultra-endurance sport. Sports Medicine (Auckland, N.Z.), 31(10), 701-715. https://doi. org/10.2165/00007256-200131100-00001

Thomas, D. T., Erdman, K. A., \& Burke, L. M. (2016). Position of the Academy of Nutrition and Dietetics, Dietitians of Canada, and the American College of Sports Medicine: Nutrition and Athletic Performance. Journal of the Academy of Nutrition and Dietetic, 116(3), 501-528. https://doi.org/10.1016/j.jand.2015.12.006.

Urdampilleta, A., Martínez-Sanz, J. M., Sánchez, S. J., \& Herms, J. Á. (2013). Protocolo de hidratación antes, durante después de la actividad físico-deportiva. European Journal of Human Movement, (31), 57-76.

Zaryski, C., \& Smith, D. J. (2005). Training principles and issues for ultra-endurance athletes. Current Sports Medicine Reports, 4(3), 165170. https://doi.org/10.1097/01.CSMR.0000306201.49315.73 